\title{
Research on Profitability and Policy Environment of Small-Micro Scale Technological Firms in China: Basing on Regional Comparative Perspective
}

\author{
Cao Yixia ${ }^{1}$, Zhang Kenan ${ }^{2}$ \\ ${ }^{1}$ Department of National Economy School, Shanghai Academy of Social Science, Shanghai, China \\ ${ }^{2}$ Department of Economy School, Fudan University, Shanghai, China
}

\begin{abstract}
China have implanted much beneficial policies towards small businesses in the past five years. However, there is never convincing empirical data presented about their effectiveness. In viewing the subject, this paper adopted a panel data from 2011 covering 31 provinces of China. The data used in this study is considered the best estimation of all small and micro businesses. This paper tried to evaluate the firms' profitability of each region to the benchmark, constructed as a general utilize level of technological resources, especially those provided by public sectors.

Index Terms - Regional high-tech industry, small business, technological environment, innovation.
\end{abstract}

\section{Introduction}

In the past five years, China imposed more and more preferential policies toward small and micro sized firms. The Ministry of Finance and the national development and Reform Commission jointly issued notice to removed 22 kinds of administrative charges on Nov.17th 2011, including management, registration and license related charges, effective from Jan.1st 2012 to Dec. 31st 2014. On Feb.1st 2012, the State Council introduced the 'national four policies' on executive meeting to further support the policy establishment. Furthermore, the decision was made to use 15 billion RMB from central fiscal to setup a small and medium businesses fund, mainly serving the venturing small and micro firms. The meeting also emphasize on speeding up the tax reform to replacing business taxes with a value-added tax as step to improve structural tax reform policy. Starting 2014, further tax reduction policies were enforced, relieving more than 6 million small businesses form taxpaying.

This research concentrates on two goals: First, generate SMFs data pool from current high technology yearbook to perform technical analysis. By obtaining regression results, thus making further indication on business policies. Second, developing a technical environment index. Both could serve as valuable reference for policy decisions.

\section{Literature Review}

In United States, small and medium sized firms not only lead to ideas of innovation, but also higher productivity. This was indicated by survey conducted by United States National Science Foundation (1976) targeted 380 innovations occurred during the period 1953 to 1973 . Small firms in other regions around the world, however, played rather minor role in innovation process. The study of National Science Foundation (1976) also calculated the contribution from small firms to innovation: highest in US (35\%), France (31\%), West Germany (26\%) and UK (23\%). Adam Adams's study (1982) in UK suggests a very similar situation that we also observe in today's China. Adams's survey (1982) indicated small firms, both innovative and non-innovative, considered they have stronger engineering skills and rather weak marketing or promotion skills. Moreover, these sample small firms also tend to have vague or no management structure, and normally search for external aid in financial or service forms (these indicating small firms. Thus, appearing as 'Lemons problem' (Akerlof's 1970), the lack of information on both sides cause adverse selection and cut off the finance channels. Information asymmetry justifies the policies to promote financial reform and setting up innovation centers as well as other institutions.

As knowledge being the core-producing factor for technological SMFs1, a patent or invention usually serves as their growth source. (Wang 2013) Therefore, technological SMFs have to take into consideration of intellectual property protection and technology markets. Thorsten Beck et al. (2005) once examined enterprise data from 54 countries to discover that influence from financial policies, laws and corruption will differ from different size of firms. Smaller companies will suffer more than large corporations. The stamina of technology market is another motivation of technical innovation, since firms can obtain profit by trading technology other than put into production. If the technical trading is very accessible and cheap, then there will be firms to innovate and trade their inventions. Hence, more participants will appear in the technology market and increased frequency of innovation can be observed, both lead to a higher competing environment. This also leads to a decline in the average cost of innovation for all technological companies, including SMFs.

\section{Technological Factors}

Two reliable yearbooks are related to technological SMFs, 'China Statistical Yearbook on Science and Technology (YST)' and 'China Statistical Yearbook on High Technology Industry (YHT)'. Unfortunately, the YST only includes medium and large sized enterprises. In YHT, however, in each statistical category, the yearbook includes both overall data and data in large-medium scale enterprises. I

\footnotetext{
${ }^{1}$ To distinguish form the widely used term SME 'small and medium sized enterprises', this paper use SMF representing 'small and micro sized firms'.
} 
subtracted the large and medium enterprises' data from the overall data to generate data of small and micro sized enterprises. I used the yearbook of 2012, so the data represents firms' performance in the year of 2011. Least squared regressions are performed to profits and each individual group separately to avoid colinearity.

Several insights were draw from regression results:

External R\&D expenditure is more productive, referring to firm's spending on R\&D activities that paid to partner firms. This could further imply that firms gain more by outsourcing R\&D activities. It can be viewed as evidence of benefits of inter-firm cooperation.

R\&D institutions are extremely profitable. A fairly independent $R \& D$ research facility built within one firm or cofounded by many firms. The extremely high (compare to other coefficients) estimated coefficient and significance suggest its contribution to firm profits. This can also be viewed as major evidence of supporting inter-firm cooperation among small and micro enterprises.

Number of patents in force does not mean higher profits. Although this statistic always appears as preferable to companies, it is not accurately valuable for technological enterprises. Firms can hold multiple patents at same time. However, most of them only choose to produce one of the most marketable. For SMFs, their restricted funding and equipment also limit their choices. Another thought is that patent does not equal to product. A company may hold several patents, yet most of them may not inventions or may be unmarketable.
Trading technology can be profitable. Normally, people treat technology as core asset for a company. Since it can bring streams of income in a long term, directly trading technology can be unwise. It is hard to trade it at its full value. The regression result of profit to technology expenditure leads to another theory. For SMFs, trading technology on one side can save time and money on producing. On the other side it can obtain cash flow. Frequently trading of technology may leads to higher knowledge spillover effect, which in turn creates better technological environment.

\section{Index Analyses}

Evaluating index system can visualize regional difference into simple numbers. Zhu et al. (2009) argued that the main indicator as a SMF's ability to continue developing is their innovating potential. They constructed innovative ability evaluating index system' under five prospects: innovation input, implementation of innovative products, marketing of innovative products and finally the innovative revenue. Gu \& Zhang (2013) used AHP methods (Analytic Hierarchy Process) with calculations of the weight of each component in their model of index to evaluate innovating ability. As limited data available, the following index was calculated base on the regression coefficients in section 3 (table 1). For validation, I ranked all 35 sample-areas according to calculated index value and real average profit value. Then, each area will receive two rank outcomes. Treating index rank as benchmark, difference in two ranks reveals whether one region's technological resources were rightly utilized into profit.

TABLE 1 Regression results

\begin{tabular}{|c|c|c|c|c|c|}
\hline & Variable & Coefficient & Std. Error & $\mathrm{t}$-Statistic & Prob. \\
\hline \multirow{5}{*}{ Profit - R\&D expenditure } & Labor cost & -0.0022 & 0.0006 & -3.8353 & 0.0006 \\
\hline & Equipment & 0.002 & 0.0013 & 1.4632 & 0.1538 \\
\hline & Government funds & 0.0009 & 0.0008 & 1.159 & 0.2556 \\
\hline & Self-raised funds by enterprise & 0.0008 & 0.0003 & 2.5527 & 0.016 \\
\hline & External expenditure & 0.0049 & 0.0015 & 3.2019 & 0.0032 \\
\hline \multirow{3}{*}{ Profit - R\&D institutions } & Number of institutions & 0.2652 & 0.0492 & 5.3859 & 0 \\
\hline & Number of personnel & 0.0153 & 0.0055 & 2.7654 & 0.0094 \\
\hline & Science \& technology expenditure & -0.0007 & 0.0003 & -2.1063 & 0.0431 \\
\hline \multirow{3}{*}{ Profit - R\&D personnel } & Total number & 0.056 & 0.0269 & 2.0801 & 0.0456 \\
\hline & Full-time personnel & -0.0147 & 0.0065 & -2.2628 & 0.0306 \\
\hline & Researchers & -0.0406 & 0.0291 & -1.3937 & 0.173 \\
\hline \multirow{3}{*}{ Profit - Patents } & Patent application & 0.0056 & 0.0105 & 0.5342 & 0.5969 \\
\hline & Invention patents application & 0.1405 & 0.0328 & 4.2814 & 0.0002 \\
\hline & Number of patents in force & -0.0131 & 0.0088 & -1.4794 & 0.1488 \\
\hline \multirow{5}{*}{ Profit - New products } & Number of new products & 0.0058 & 0.0319 & 0.1817 & 0.8571 \\
\hline & Products development & 0.0005 & 0.0002 & 2.5229 & 0.0172 \\
\hline & Output value of new products & -0.0001 & 0.0001 & -0.7887 & 0.4365 \\
\hline & Sales revenue & 0.0001 & 0.0001 & 0.5806 & 0.5658 \\
\hline & Exports & 0 & 0.0001 & -0.5893 & 0.5601 \\
\hline \multirow{4}{*}{ Profit - Technology expenditure } & Acquisitioned foreign technology & 0.0014 & 0.0006 & 2.2334 & 0.0329 \\
\hline & Technology assimilation & 0.0216 & 0.0049 & 4.3867 & 0.0001 \\
\hline & Purchase of domestic technology & 0.0105 & 0.0027 & 3.9156 & 0.0005 \\
\hline & Technical renovation & 0.0004 & 0.0001 & 3.3856 & 0.0019 \\
\hline
\end{tabular}


TABLE 2 Index results and rank comparison

\begin{tabular}{|c|c|c|c|c|c|c|}
\hline Region & Profit/100 m & Rank by profit & Region & Indexvalue & Rank by index & rank difference \\
\hline Anhui & 34.29 & 16 & Anhui & 305.08 & 12 & 4 \\
\hline Beijing & 54.06 & 11 & Beijing & 370.57 & 10 & 1 \\
\hline Chongqing & 9.73 & 26 & Chongqing & 45.62 & 28 & -2 \\
\hline Eastern Region & 803.25 & 2 & Eastern Region & 5082 & 2 & 0 \\
\hline Fujian & 26.68 & 21 & Fujian & 210.82 & 18 & 3 \\
\hline Gansu & 3.47 & 31 & Gansu & 13.51 & 30 & 1 \\
\hline Guangdong & 110.66 & 6 & Guangdong & 752.23 & 7 & -1 \\
\hline Guangxi & 35.04 & 15 & Guangxi & 93.3 & 21 & -6 \\
\hline Guizhou & 12 & 24 & Guizhou & 269.78 & 15 & 9 \\
\hline Hainan & 5.89 & 28 & Hainan & 46.05 & 27 & 1 \\
\hline Hebei & 33.41 & 17 & Hebei & 67.47 & 24 & -7 \\
\hline Heilongjiang & 9.77 & 25 & Heilongjiang & 60.45 & 25 & 0 \\
\hline Henan & 58.13 & 10 & Henan & 155.34 & 19 & -9 \\
\hline Hubei & 31.05 & 19 & Hubei & 213.84 & 17 & 2 \\
\hline Hunan & 51.86 & 12 & Hunan & 274.2 & 14 & -2 \\
\hline Inner Mongolia & 7.68 & 27 & Inner Mongolia & 7.51 & 31 & -4 \\
\hline Jiangsu & 207.85 & 4 & Jiangsu & 1414.2 & 3 & 1 \\
\hline Jiangxi & 29.74 & 20 & Jiangxi & 133.57 & 20 & 0 \\
\hline Jilin & 32.64 & 18 & Jilin & 59.11 & 26 & -8 \\
\hline Liaoning & 61.81 & 9 & Liaoning & 293 & 13 & -4 \\
\hline Middle Region & 259.06 & 3 & Middle Region & 1237.43 & 4 & -1 \\
\hline Ningxia & 1.43 & 33 & Ningxia & 4.95 & 32 & 1 \\
\hline Qinghai & 1.02 & 35 & Qinghai & 0.39 & 35 & 0 \\
\hline Shaanxi & 16.33 & 23 & Shaanxi & 88.38 & 22 & 1 \\
\hline Shandong & 114.41 & 5 & Shandong & 371 & 9 & -4 \\
\hline Shanghai & 44.47 & 13 & Shanghai & 382.21 & 8 & 5 \\
\hline Shanxi & 3.91 & 30 & Shanxi & 28.33 & 29 & 1 \\
\hline Sichuan & 42.65 & 14 & Sichuan & 349.38 & 11 & 3 \\
\hline Tianjin & 24.71 & 22 & Tianjin & 228.71 & 16 & 6 \\
\hline Tibet & 1.66 & 32 & Tibet & 4.1 & 33 & -1 \\
\hline Western Region & 95.38 & 7 & Western Region & 859.2 & 5 & 2 \\
\hline Xinjiang & 1.34 & 34 & Xinjiang & 3.45 & 34 & 0 \\
\hline Yunnan & 5.75 & 29 & Yunnan & 79.63 & 23 & 6 \\
\hline Zhejiang & 84.25 & 8 & Zhejiang & 852.44 & 6 & 2 \\
\hline Total & 1157.69 & 1 & Total & 7178.64 & 1 & 0 \\
\hline
\end{tabular}

In last column, negative numbers are more important than positive numbers. Negative number indicates the profit ranking is lower than estimate ranking. This directs to an under realization of technological resources in those regions. For those regions with positive ranking difference, we can say that they make use of technological resources more efficiently than other regions. However, the index cannot tell us whether the technological resources are fully employed.

\section{Policy Indications}

Among all indicators discussed in the above analysis, the following factors are potentially influenced directly through business polices: government fund (as R\&D expenditure), R\&D institutions, and technology expenditures. Policies can directly affect these factors through grants, incubators, state $R \& D$ facilities and regulation on trading of technology. Other vital factors as personnel, new products and patent than influenced by policies more mildly and indirectly. I started by look back to policies in some major provinces and cities from 2010 to 2011. 
TABLE 3 SMF policies (2010-2011)

\begin{tabular}{|c|c|}
\hline & INTERNATIONAL COOPERATION \\
\hline BEIJING & Cooperation with foreign high-tech SME parks \\
\hline SHANGHAI & Organize SMEs to participate in varies expos, organized visit to Kashi as qualification examine of suppliers; cut-off bid fees for participants \\
\hline JIANGSU & Build cooperation and communication platform, organize professional exhibitions; organize trade negotiations with SMEs in Marche, Italian \\
\hline \multirow[t]{2}{*}{ SICHUAN } & Organize SMEs to participate in APEC SME Technology Conference \\
\hline & FINANCIAL SERVICE \\
\hline JIANGSU & Pushing the use of SME collective bonds, widen up direct financing channels for SMEs \\
\hline ZHEJIANG & $\begin{array}{l}\text { Focus on the existed "venture capital platform for SMEs"; "Zhejiang small business multi-service platform", "Zhejiang Investment and Financing } \\
\text { SME Service Alliance", "Zhejiang Mergers and acquisitions Club" and other platforms; hold Zhejiang Fair for investment and Financing of SMEs }\end{array}$ \\
\hline \multirow[t]{2}{*}{ SHAANXI } & Issued total 1 billion RMB long-term notes for SMEs \\
\hline & CRIDET WARRANTY SERVICE \\
\hline ZHEJIANG & Test microcredit guarantee insurance; invested one billion RMB to established re-guarantee companies for SMEs \\
\hline \multirow[t]{2}{*}{ SHAANXI } & Established SME credit guaranty association \\
\hline & PUBLIC SERVICE \\
\hline BEIJING & $\begin{array}{l}\text { Form municipal coordinating agency for SME development and create specific guidelines for government procurement as a supporting tool for } \\
\text { SMEs }\end{array}$ \\
\hline SHANGHAI & Improved the existing public service platform; strengthen enterprise running test \\
\hline JIANGSU & Achieved full coverage of SME Service; promote intensive cluster development; opened free legal service hotline 96885 \\
\hline ZHEJIANG & Strengthen the construction of industry associations for SMEs \\
\hline SICHUAN & A 3-5 years constructive plan of public service platform and network system \\
\hline SHAANXI & $\begin{array}{l}\text { Start to built a Public service platform for SMEs; officially launched international trade public service platform for SMEs; established economic } \\
\text { and social develop service group also known as SME legal service group }\end{array}$ \\
\hline BEIJING & "Beijing SMF entrepreneurial base set-up rule" is being drafting \\
\hline SHANGHAI & Promote SME branding; officially launched the "SME training program leading talent program" \\
\hline JIANGSU & $\begin{array}{l}\text { Identified the first batch of } 45 \text { SMEs with innovation capacity; and } 50 \text { major supported SMEs; To accelerate the elimination of backward } \\
\text { production capacity }\end{array}$ \\
\hline ZHEJIANG & Developing Enterprise counseling; promote entrepreneurial base and incubator \\
\hline SICHUAN & Fully implementation of SME development projects and the "little giant" enterprise incubation program \\
\hline \multirow[t]{2}{*}{ SHAANXI } & Present "Chief Engineer" honors to selected engineers from SMEs \\
\hline & LAWS AND POLICIES \\
\hline BEIJING & Start the local legislation process of 'SME advancing Law, seek to be included in 2012 City People's Congress legislative plan \\
\hline SHANGHAI & "Promote SME development regulations in Shanghai " enforced from June 1st 2011 \\
\hline JIANGSU & Issued " policy advice on improving the business environment for SMEs " \\
\hline ZHEJIANG & $\begin{array}{l}\text { Issued "notice on adjust industrial structure, maintain growth control energy consumption and increase income", launched seven plans to help } \\
\text { SMFs' restructuring and development }\end{array}$ \\
\hline \multirow[t]{2}{*}{ SHAANXI } & Develop assessment methods of SME Development Goals \\
\hline & INFORMATION TECHNOLOGY \\
\hline SHANGHAI & $\begin{array}{l}\text { Allocated } 10 \text { million RMB to boost SMEs become "E business"; launched the "SME information application demonstrating enterprise" trial } \\
\text { program }\end{array}$ \\
\hline ZHEJIANG & Established of "millions" SME foster sourcing pool \\
\hline SICHUAN & Started SMEs e-commerce applications promoting; first SME information service system was put into use in Panzhihua \\
\hline
\end{tabular}

Source: "China Small and Medium Enterprises Yearbook 2011" and revised by author 
Next, we summarized five features from collected information about small business policies in U.S.A, U.K. and Canada.

1. Not contribute direct finance to small and micro enterprises like massive subsidies, government funds. Funds normally go through market segment reaching out to small and micro enterprises.

2. As crediting, U.S. and Canada establish a hierarchical security system; Britain mainly works with banks.

3. All apply a combination of different variety of tax incentives.

4. Improve the percentage of small and micro enterprises bidding for government procurement.

5. Create different forms of national innovation encourage programs, leaded and supervised by government.

From above information, the following suggestions are provided for policy makers. The key still rely on a selfmotivated financial market and policies about effective risk control.

Technological SMFs tend to have higher capital requirements. Meanwhile, technology innovation activity has a high-risk expectation, diminishing banks' incentive to lend to small businesses. Government can be of help in two paths as providing policy support. First, through collective bonds, collective notes, collective trust aims to diversify risks. But in 2011, a burst of Wenzhou "closures" appeared among small firms. Some scholars believe it is due to the 'risky' parts of the whole bundle, refers to the bankruptcy of firms with poor performance end up dragging down those firms with expected returns. Since they involved in same loan plan, developing new forms of financing or in this case the collective financing needs necessary crediting process. In order to make market capital accessible for SMFs, a reasonable allocation of risk and rational assessment of the enterprise are necessary. Another path is introducing fiscal subsidies or creates government-funded projects. Still, as government funds for $\mathrm{R} \& \mathrm{D}$, fiscal subsidy and reduction should also act as minor policy. We should learn from foreign experiences, establish specific funds and a unified charging department for SMFs to regulate the granting amount and funding system. Protecting taxpayers' money, hence national funds, array of crediting system also needed to evaluate small businesses.

Government procurement ought to play significant role, but this was not found in past policies observed. At least it was not used as major tool. Government should, through government procurement programs create demand for small and micro enterprises and their scientific output, helping them gain competence and market share. To ensure these purchasing are valuable, more detailed policies pertain to the bidding process should be designed. Like increase the percentage of SMFs in bidding by cutting down cost to bid. Or allow SMFs to form bidding groups or alliance to compete in the bidding.

Judging from the above tables, one can tell funding is the main contributor for science and technology enterprise development. National science and technology projects as well as capital investment in high-tech industry are driving roles in prompting a better technological environment. From previous discussion, we know that government funding played minor role than external $\mathrm{R} \& \mathrm{D}$ expenditure. Therefore, one suggestion for small and micro firms is to form clear division of labor and then cooperate with each other. Meaning some SMFs focusing on R\&D activities while some of them buy R\&D outputs. Make more connection with R\&D institutions. Data confirmed the high productivity of R\&D institutions. Small and micro firms in this sense should also develop collective R\&D research facilities. Many evidences from this research suggesting that small and micro firms should rely more one external resources in order to generate higher profits.

\section{Summary}

This article made a comprehensive analysis base on the small business data from 2011, and the index base on the regression displayed further policy implications for evaluating regional technological environment. Difference in index value ranking and profit ranking indicates whether technological resources are effectively used. Meanwhile, this research still bears several flaws may yield the conclusion. It ignores the aggregation economy effect, thus no factors about geographic area or density indicator were considered. This might undervalue some regions' profit potential thus index estimation will be lower than it's real technological to profit influence. Besides, this index only could be used to explain normal factor that exists in all regions.

\section{References}

[1] Adams, A. (1982). Barriers to product innovation in small firms: Policy implications. International Small Business Journal, 1(1), 67-86.

[2] Akerlof, G. A. (1970). The market for" lemons": Quality uncertainty and the market mechanism. The quarterly journal of economics, 488-500.

[3] Fleisher, Belton, Haizheng Li, and Min Qiang Zhao. Human capital, economic growth, and regional inequality in China. Journal of Development Economics, 2010, (02): 215-231.

[4] National Science Foundation (1976). Indicators of international Trends in Technological innovation. NSF-C889, Washington.

[5] Thorsten Beck, Asli Demirgu, C. Kunt and Vojislav Maksimovic. Financial and Legal Constraints to Growth: Does Firm Size Matter? Journal of Finance, 2005, (02): 137-177.

[6] Vernon, R. (1966). International investment and international trade in the product cycle. The quarterly journal of economics, 190-207.

[7] Welsh, Dianne, et al. Microenterprise Performance and Microenterprise Zones (MEZOs) in China. , Management Decision, 2012, (01): 2-2

[8] Gu, Chaobing \& Zhang, Zhengya. Index of Science and technology Small and micro businesses development. Science and technology economy market. 2013, (06):69-72.

[9] Jia, Pinrong. Policy direction of technological SMEs. Corporation Research. 2012,(15):56-58

[10]Wang, Junfeng \& Wang, Yan. Problems about developments of small and micro businesses in China, Corporation Research. 2012, (09): 92-99.

[11]Wang, Huilong. Knowledge right protection for technological small and micro businesses. Chongqing Social Science. 2013, (03): 27-34.

[12]Zhu, Jian \& Sha, Weijing. Developing industrial clustering being an new vision of lowering small businesses' financing cost. Economic Review. 2013, (04):109-112. 